\title{
Self-potential time series analysis in a seismic area of the Southern Apennines: preliminary results
}

\author{
Gerardo Di Bello $\left({ }^{1}\right)$, Vincenzo Lapenna $\left({ }^{2}\right)$, Celestina Satriano $\left({ }^{3}\right)$ and Valerio Tramutoli $\left({ }^{1}\right)$ \\ $\left({ }^{1}\right)$ Dipartimento di Ingegneria e Fisica dell'Ambiente, Università della Basilicata, Potenza, Italy
$\left({ }^{2}\right)$ Istituto di Metodologie Avanzate di Analisi Ambientale, Area della Ricerca del C.N.R., Tito (PZ), Italy \\ $\left.{ }^{3}\right)$ Dipartimento di Chimica, Università della Basilicata, Potenza, Italy
}

\begin{abstract}
The self-potential time series recorded during the period May 1991 - August 1992 by an automatic station, located in a seismic area of Southern Apennines, is analyzed. We deal with the spectral and the statistical features of the electrotelluric precursors: they can play a major role in the approach to seismic prediction. The time-dynamics of the experimental time series is investigated, the cyclic components and the time trends are removed. In particular we consider the influence of external noise, related to anthropic activities and meteoresults parameters, and pick out the anomalies from the residual series. Finally we show the preliminary which occurred in the area.
\end{abstract}

Key words geoelectrical precursors - time series - seismic prediction

\section{Introduction}

Changes in many geoelectric parameters are observed before and during an earthquake and many models have been proposed to describe, in the time domain, the anomalies in the natural electric field measured near the epicentral area. These effects can be related to an underground fluid diffusion (Nur, 1972) and/or to a piezoelectric effect (Sornette and Sornette, 1990). The correlation between the observed anomalies in the self-potential time series, which are evaluated measuring the voltage differences between two electrodes put in the ground, and the occurrence of a seismic event has been studied by many authors in recent years (Mogi, 1985; Rikitake, 1979, 1988). In many countries some successes were obtained in forecasting earthquakes: however, a com- plete physical theory about these precursors, is not yet available. The phenomenon is complex: many parameters play an important role in the dynamics of the process and some of them are related to external noise.

A scientific approach to the problem could be based on an analysis of the space and time patterns of the natural electric field, around a focal region, continuously monitored by a network and on the application of advanced statistical methods to pick out the anomalies related to the seismic event. In many cases (Varotsos and Alexopoulos, 1984a,b), we cannot evaluate the efficiency of the electric precursors because the occurrence probability of the seismic event is high and, on the other hand, a statistical analysis of the observed anomalies is omitted (Burton, 1985). Besides, it is necessary to distinguish in the self-potential time series the contribution of many factors (storm, industrial activities, rainfall cycle etc.) not directly related to the earthquakes. 


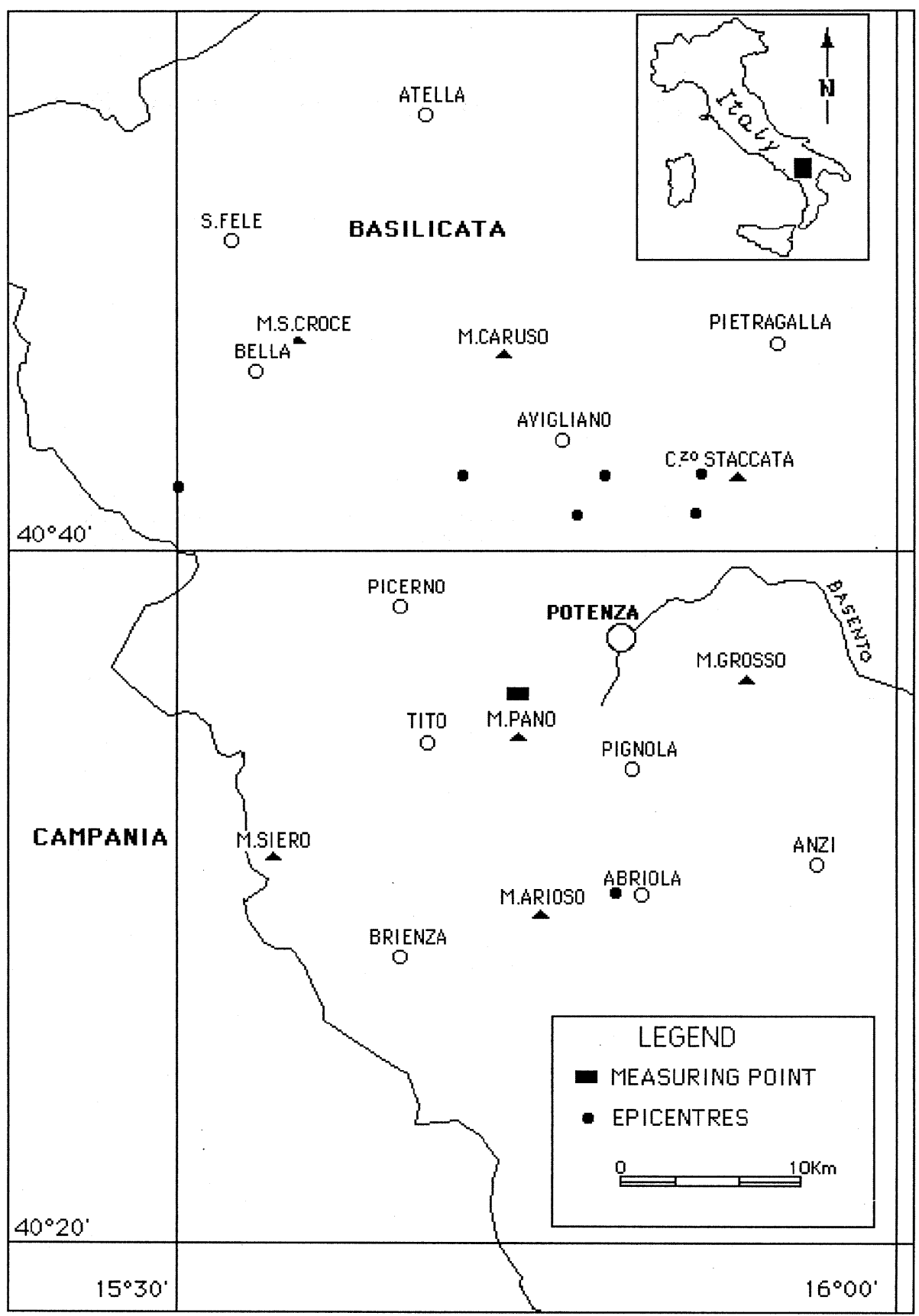

Fig. 1. The map localizes the measuring station and the epicentres of the earthquakes observed in the period May 1991-August 1992. 
Table I. Catalogue of the earthquakes observed in the area during the period May 1991-August 1992.

\begin{tabular}{ccccc}
\hline \hline \multicolumn{2}{c}{ Date } & Latitude & Longitude & Magnitude \\
\hline May, 26 & 1991 & $40^{\circ} 42^{\prime}$ & $15^{\circ} 48^{\prime}$ & 4.7 \\
May, 27 & 1991 & $40^{\circ} 41^{\prime}$ & $15^{\circ} 47^{\prime}$ & 3.4 \\
May, 27 & 1991 & $40^{\circ} 42^{\prime}$ & $15^{\circ} 48^{\prime}$ & 3.1 \\
May, 28 & 1991 & $40^{\circ} 42^{\prime}$ & $15^{\circ} 52^{\prime}$ & 3.0 \\
June, 6 & 1991 & $40^{\circ} 30^{\prime}$ & $15^{\circ} 48^{\prime}$ & 3.3 \\
June, 6 & 1991 & $40^{\circ} 42^{\prime}$ & $15^{\circ} 42^{\prime}$ & 3.1 \\
May, 8 & 1992 & $40^{\circ} 41^{\prime}$ & $15^{\circ} 52^{\prime}$ & 3.5 \\
July, 2 & 1992 & $40^{\circ} 42^{\prime}$ & $15^{\circ} 30^{\prime}$ & 3.2 \\
\hline
\end{tabular}

In this work we are concerned with the statistical analysis of a self-potential time series recorded by an automatic station in a seismic area of the Southern Apennines (fig. 1). The area is localized in the Basilicata Region around the town of Potenza, that, in recent years, has been hit by many earthquakes with magnitudes $M>3$ (table I). In particular the town of Potenza has been damaged many times over the centuries and historical documents allow us to evaluate the seismic sequences (Pellettieri, 1992). The seismic risk in this region is very high and this area represents an optimum test site to analyze the efficiency of the electric precursors.

We use the periodogram and maximum entropy techniques to evaluate and remove the predominant components in the spectrum of the self-potential time series. The filtered data are then correlated with the meteo-climatic variables, namely air temperature and daily precipitations. Finally we pick out the anomalies in the residual time series and we show the preliminary results of the correlation with the local seismic events.

An advanced statistical analysis of the temporal dynamics of the self-potential time series can give useful information on the physical law needed to describe the phenomenological aspects of electrotelluric precursors. This approach, combined with a large network to measure the space and time patterns of telluric currents, would lead to an estimate of the efficiency of geoelectric precursors.

\section{Data}

In May 1991 we installed two couples of electrodes along the N-S and E-W directions with a spacing of $100 \mathrm{~m}$ and $120 \mathrm{~m}$ respectively, in the research area of the National Research Council located in Tito Scalo (Potenza, Italy). Measurements of voltage differences between the electrodes are performed and controlled by a data logger. The experimental apparatus is controlled by a personal computer in which we implemented ad hoc software to store and analyze the measured voltage differences. The sampling interval of the system is $\Delta t=5 \mathrm{~s}$ and a mean value is calculated on 60 measurements and stored on a magnetic support (fig. 2).

The automatic station is a multichannel system: some channels, since April 1991, have been used to measure many meteo-climatic parameters: air temperature, radiance, humidity, etc.... A cross-correlation between the time series of these parameters and the self potential data will be shown in the next section.

The electrodes are made of copper bars working buried at $1 \mathrm{~m}$ depth. In September 1991 we also installed two couples of non-polarizable probes near the copper electrodes. As shown in fig. 3a,b the data from the two electrode types are not significantly different and, for the sake of brevity, in the following sections we will describe only the results obtained using the copper bars.

Only in the period July 1991-September 


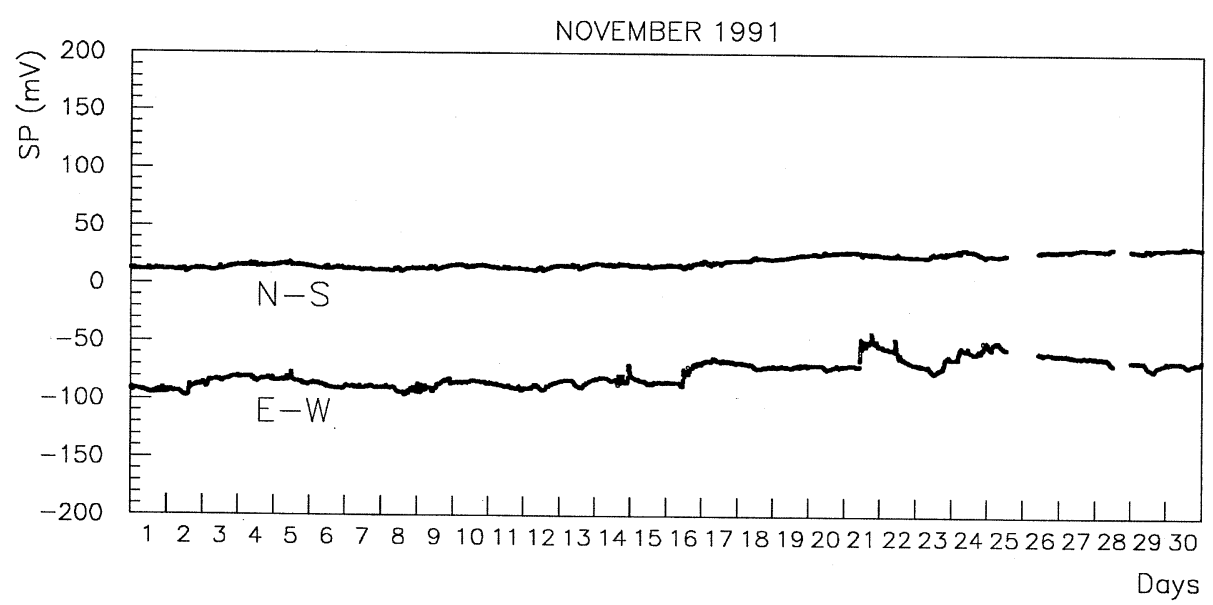

Fig. 2. Plot of the voltage signals measured along the two directions N-S and E-W during November 1991.

1991 there was data missing, the global ratio between missing and measured values is lower than $20 \%$.

\section{Spectral and statistical features of the self-potential time series}

In this section we study the infuence of external geophysical parameters such as air temperature cycle, humidity etc... on the self-potential time series. To remove the external noise we studied the spectral features of the time series and filtered the contaminated components in the power spectrum. Before starting with this analysis we calculated the daily mean value for each day, in this way we performed a low-pass filter and removed the influence of sporadic transients and the effects related to diurnal change of the ground temperature.

The time series we analyzed are made up of the daily mean values of voltage differences measured in the directions N-S and E-W during the period May 1991-August 1992 (fig. 3a,b).

We used the classical approach based on the periodogram technique (Jenkins and Watts, 1968) to calculate the power spectrum of the experimental data. To check and distinguish harmonic components inside small frequency intervals we applied the maximum entropy method (Burg, 1978).

Given a discrete time series $X(n \Delta t)$, the periodogram power is

$$
P(i)=\frac{A^{2}(i)+B^{2}(i)}{2}
$$

for $i=1,2, \ldots \frac{N}{2}-1$, the coefficients $A(i) \mathrm{e}$ $B(i)$ are defined by

$$
\begin{aligned}
& A(i)=\frac{2}{N} \sum_{n=1}^{N} X(n \Delta t) \cos \left(\frac{2 \pi n i}{N}\right) \\
& B(i)=\frac{2}{N} \sum_{n=1}^{N} X(n \Delta t) \sin \left(\frac{2 \pi n i}{N}\right)
\end{aligned}
$$

where $N$ is the number of the available data.

For $i=\frac{N}{2}$ we have

$$
\begin{aligned}
& A\left(\frac{N}{2}\right)=\frac{1}{N} \sum_{n=1}^{N} X(n \Delta t) \cos (n \pi) \\
& B\left(\frac{N}{2}\right)=0
\end{aligned}
$$



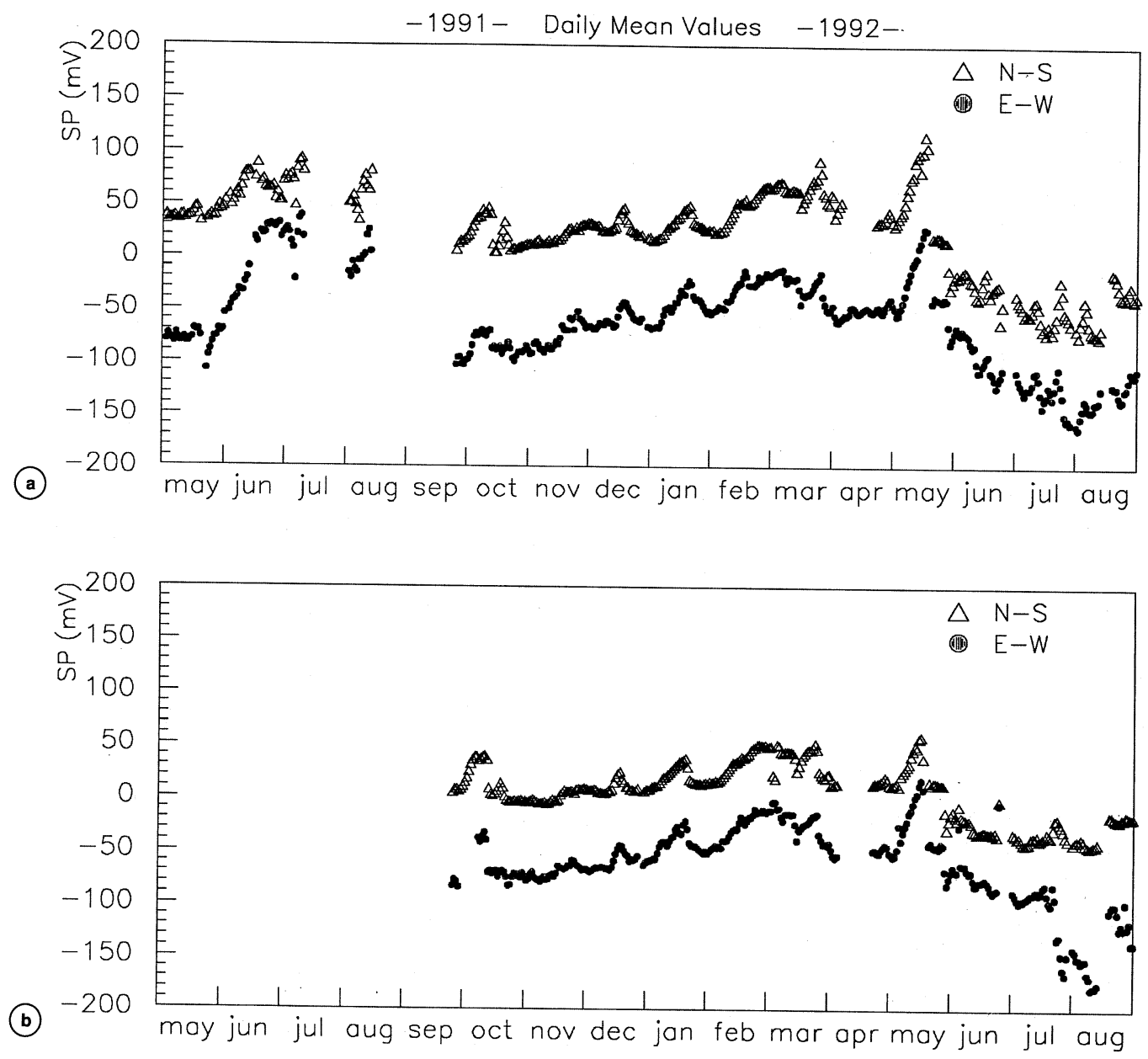

Fig. 3a,b. Daily mean values of the self-potential time series: a) values measured with the copper bar electrodes; b) values measured with impolarizable electrodes.

The periodogram power spectra obtained applying eqs. (3.2) and (3.3) are plotted in fig. $4 a, b$. The second and the third harmonic explain, throughout the time series analyzed, almost $50 \%$ of the variance, while the first harmonic contribution is negligible. We can conclude that in the time series two strong cyclic components can be distinguished without linear trends, while for other frequencies the spectrum can be considered flat.
A powerful method to distinguish cyclic components with very close frequencies is the maximum entropy technique. The basic idea which underlies the procedure is to assume that the time series are composed of a periodic pattern and a white noise, thus we remove the periodic patterns by generating new data according a suitable linear filtering operation which produces only white noise. The technique consists of modeling the data with an autoregres- 

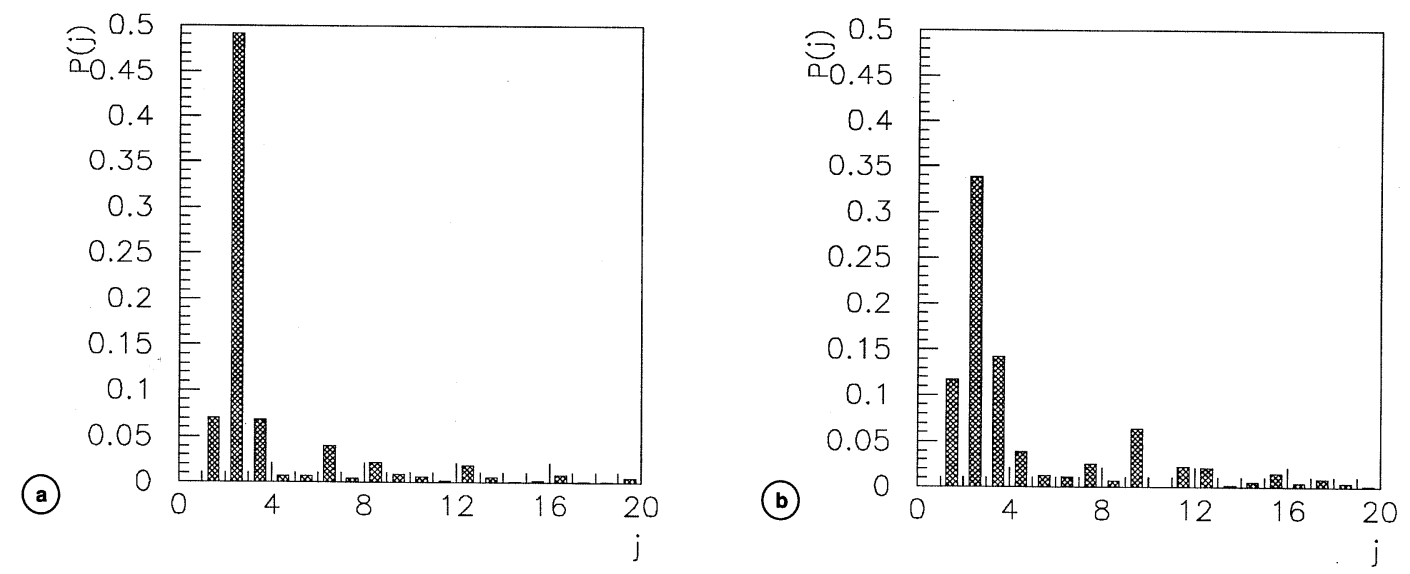

Fig. 4a,b. Periodogram power spectra of the time series plotted in fig. 3a; a) and b) refer to the results for the values measured along N-S and E-W directions respectively.
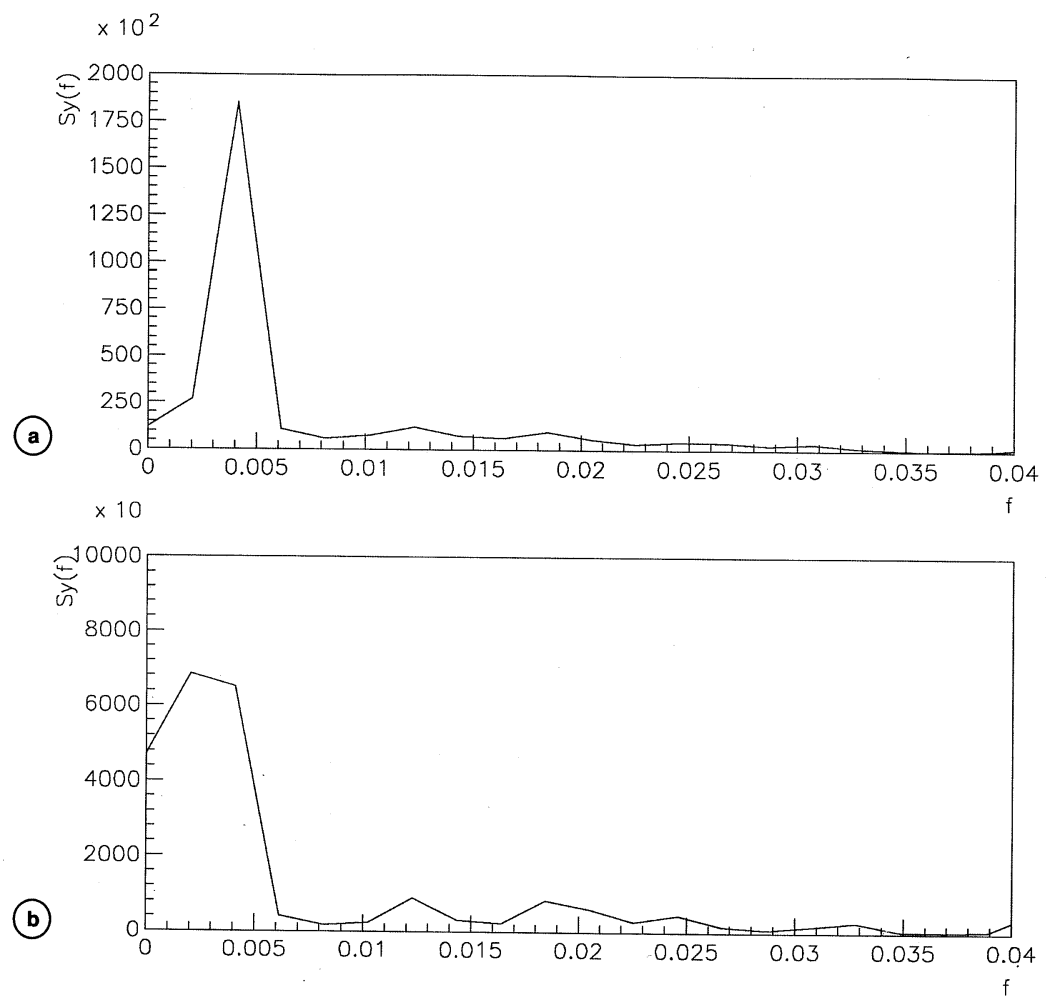

Fig. 5a,b. Maximum entropy spectra of the time series shown in fig. 3a; a) and b) refer to the N-S and E-W directions respectively. 
sive process (Box and Jenkins, 1976). In our case we use Burg's estimation procedure (Burg, 1968) as implemented by Andersen (1974).

The spectrum is

$$
S_{x}(f)=\frac{\sigma_{x}^{2} \Delta t}{\left[1-\sum_{j=1}^{p} \hat{\phi}_{j} \cdot \exp (2 \pi j f \Delta t)\right]^{2}}
$$

where $\sigma_{x}^{2}$ is the sampling variance of the $X(n \Delta t)$ series, $f$ is the ordinary frequency limited by Nyquist interval and $\phi_{j}$ are the coeffi- cients of the autoregressive model fitted to the data (Andersen, 1974). The maximum entropy spectra obtained are shown in fig. 5a,b: they confirm the previous results.

The strong cyclic components we are discriminating in the spectrum have very low frequencies and could be related to the temperature and/or rainfall periodicity. Before analyzing the correlation between the self-potential time series and the seismic sequences, we filtered the first two components in the spectrum (fig. 6a,b, full line) and normalized the time series by the variance obtaining the residual
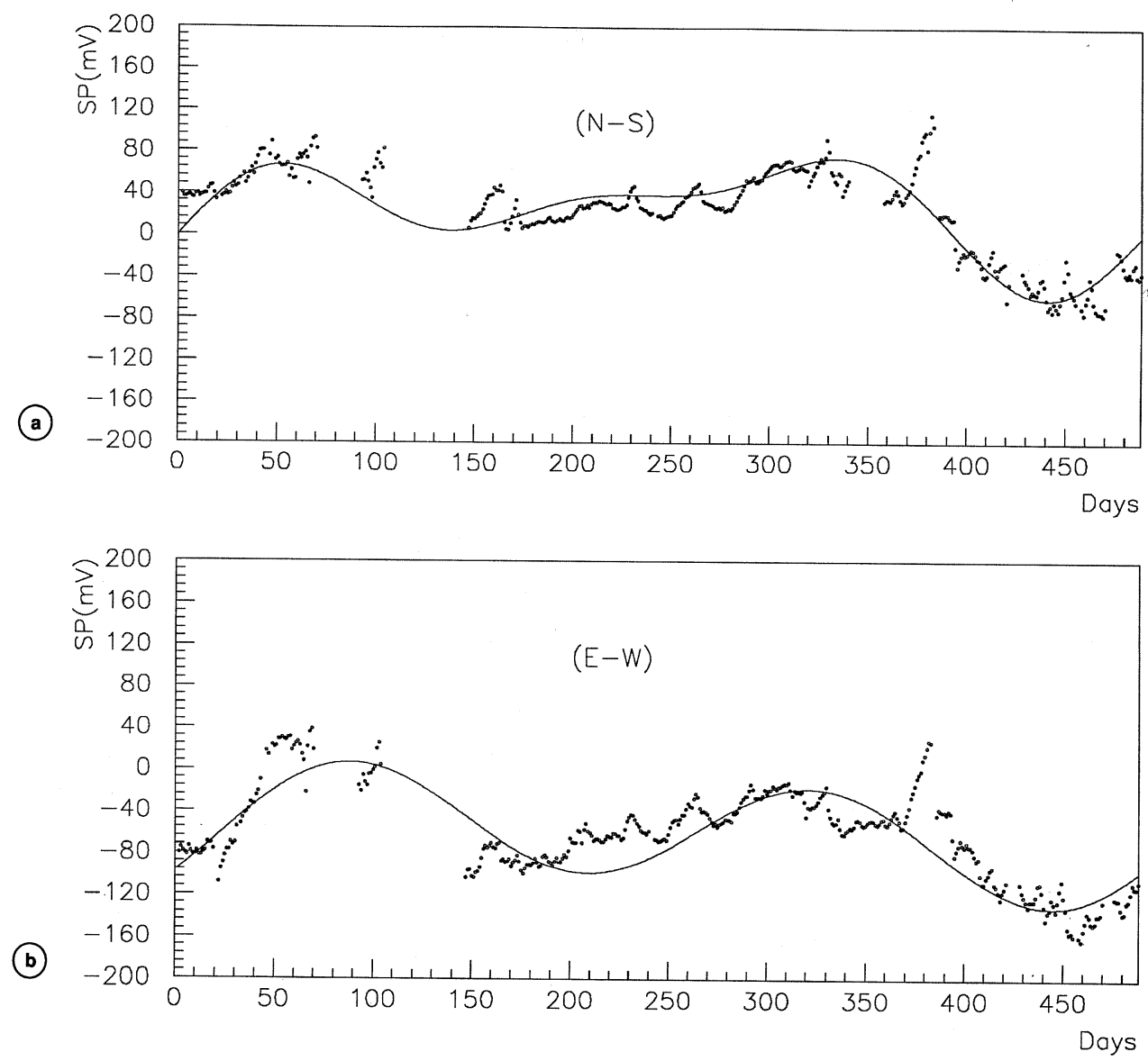

Fig. 6a,b. Fit between the time series and the values obtained from the first two cyclic components of the periodogram spectrum: a) and b) refer to the values measured along N-S and E-W directions respectively. 

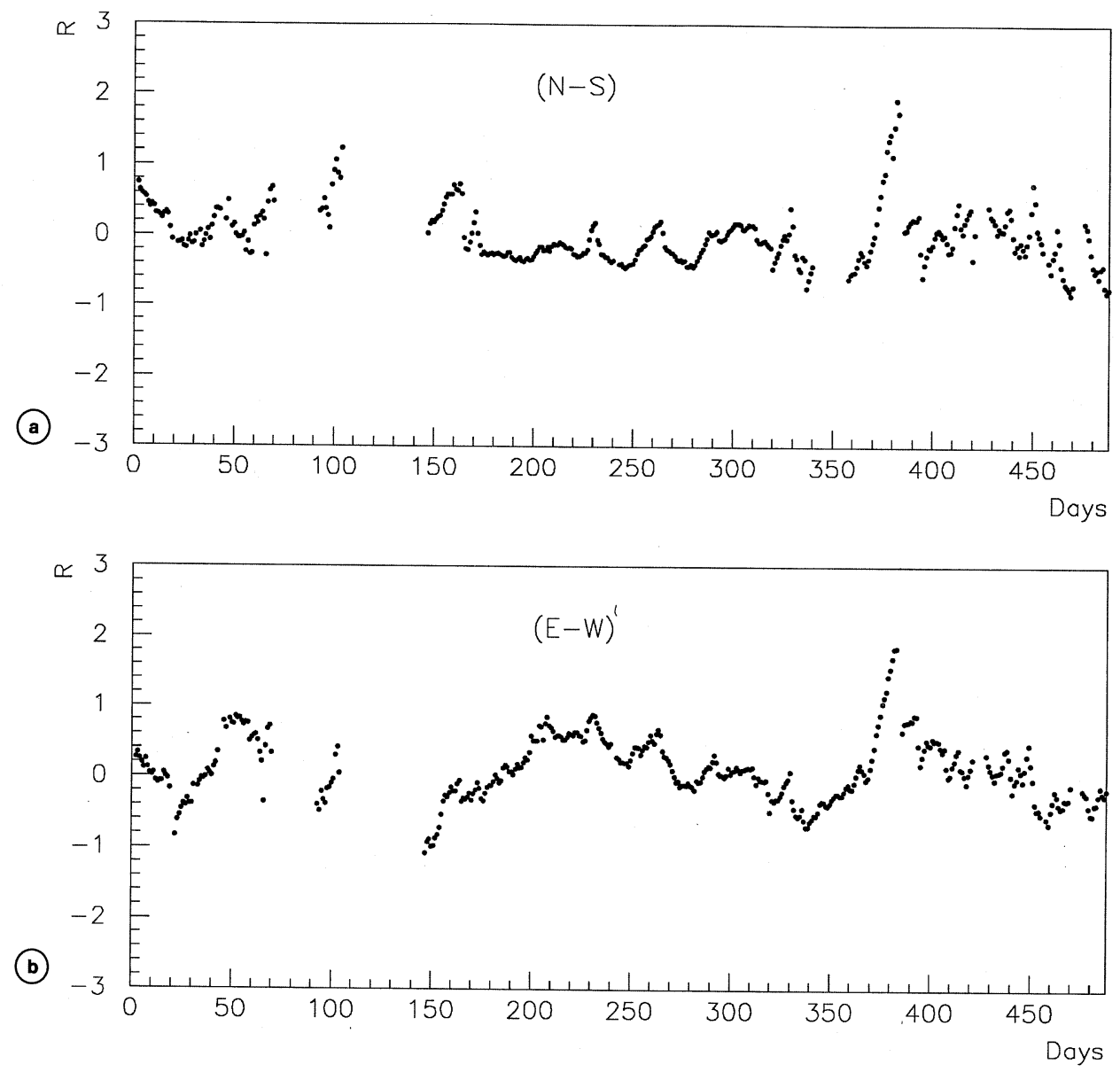

Fig. 7a,b. The figure reports the residual time series: a) and b) refer to the N-S and E-W directions respectively.

time series with zero mean and unit variance. The residual values are given by the following formula:

$$
\begin{gathered}
R(n \Delta t)= \\
=\frac{X(n \Delta t)-\sum_{i=1}^{2}\left[\hat{A}(i) \cos \left(\frac{2 \pi i n}{N}\right)+\hat{B}(i) \sin \left(\frac{2 \pi i n}{N}\right)\right]}{\sigma_{x}^{2}}
\end{gathered}
$$

for $n=1,2, \ldots, N$, where $\sigma_{x}^{2}$ is the sampling variance of $X(n \Delta)$, and $\hat{A}(i)$ and $\hat{B}(i)$ are estimates of the Fourier coefficients. The residual time series are shown in fig. $7 \mathrm{a}, \mathrm{b}$.

\section{Cross-correlation with seismic sequences: preliminary results}

In this section we compare the self-potential residual time series with the seismic sequences recorded by the local network of «Centro di Geomorfologia Integrata per le Aree del Me- 
diterraneo» connected to the national network of «Istituto Nazionale di Geofisica». During the measuring period inside a $50 \mathrm{~km}$ radius with its centre in the city of Potenza many seismic events with magnitude $M \geq 3$ have occurred (table I).

Before comparing the residual time series with the seismic sequences we studied the cross-correlation of all residual time series with the air temperature and humidity time series (fig. 8a,b). An estimate of the normalized cross-correlation coefficients is

$$
\begin{gathered}
\hat{\rho}_{i j}(k)= \\
=\frac{\frac{1}{N} \sum_{n=1}^{N-k}\left[X_{i}(n \Delta t)-\bar{X}_{i}\right]\left[X_{j}((n+k) \Delta t)-\bar{X}_{j}\right]}{\sqrt{\hat{\rho}_{i i}(0) \hat{\rho}_{j j}(0)}}
\end{gathered}
$$

where $X_{i}(n \Delta t)$ represents:

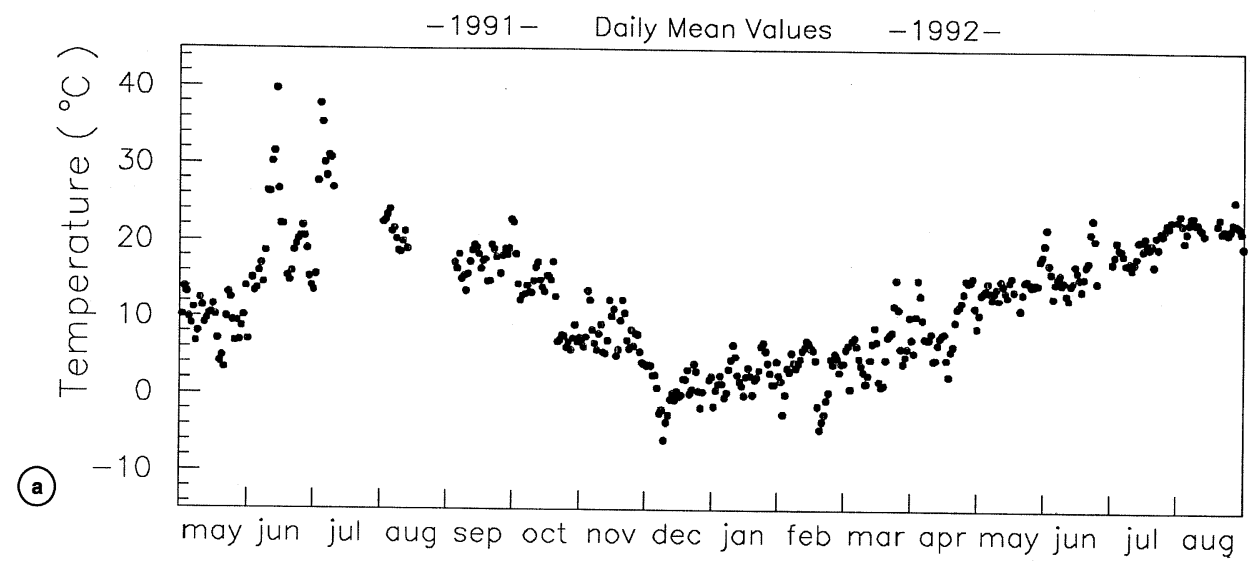

(b)

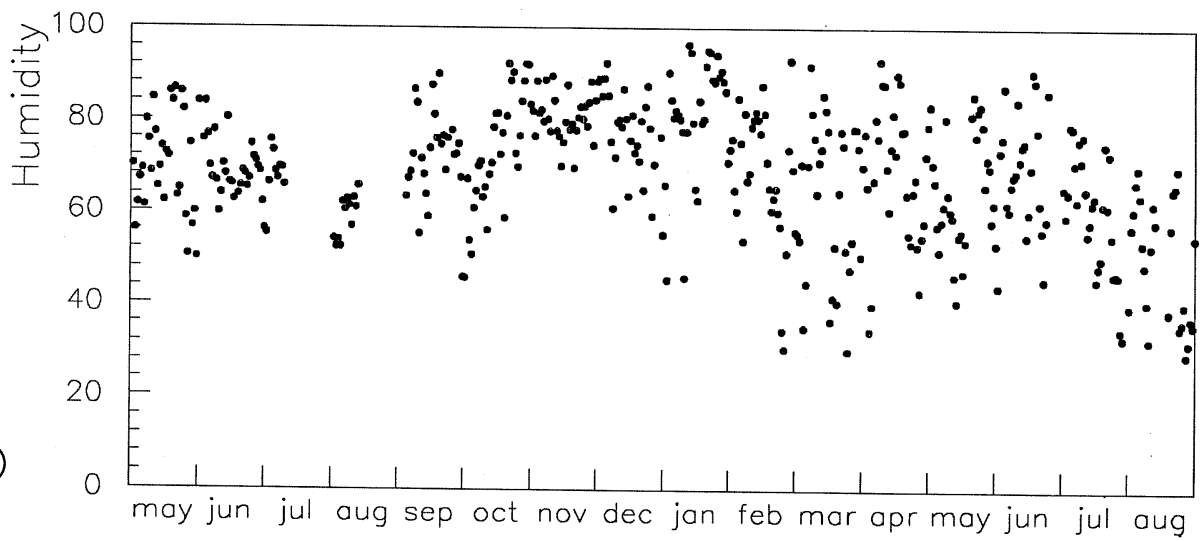

Fig. 8a,b. a) Reports the air temperature time series recorded at the station during the period May 1991August 1992; b) reports the air humidity time series recorded in the same period. 
for $i=1$, the residual time series $(\mathrm{N}-\mathrm{S})$; for $i=2$, the residual time series (E-W); for $i=3$, the air temperature time series; for $i=4$, the air humidity time series;

the $\bar{X}_{i}$ and $\hat{\rho}_{i i}(0)$ denote the mean value and the variance of the $i$-th time series, respectively. For two processes completely uncorrelated the expected values of the cross-correlation coefficients are zero for all lags and the variance of the estimator $\rho_{i j}$ is $\sigma_{c}^{2}=\frac{1}{N}$ (Jenkins and Watts, 1968). Hence the $95 \%$ confidence limits are $\pm 2 \hat{\sigma}_{c}$ and the coefficients, obtained from eq.
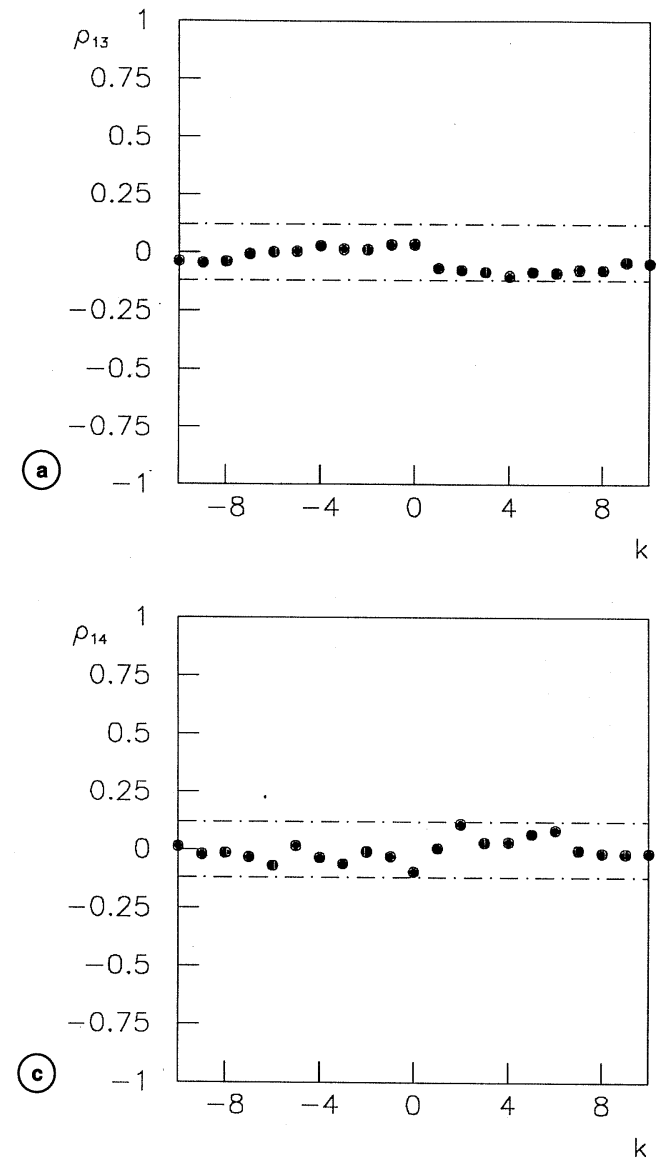

(4.1), fall in the confidence interval (band limited by two dashed lines in fig. 9a-d) for all values of $k$, so we can consider the residual time series not influenced by external noise related to meteo-climatic change.

Finally we can compare the data with the seismic sequences: a strong anomaly in the residual time series (the values are greater than $2 \sigma$ ) is present in May 1992 and many transients are located in the interval June 1991July 1991. In the same periods we observe earthquakes of magnitude $M \geq 3.2$ in the area (fig. 10).
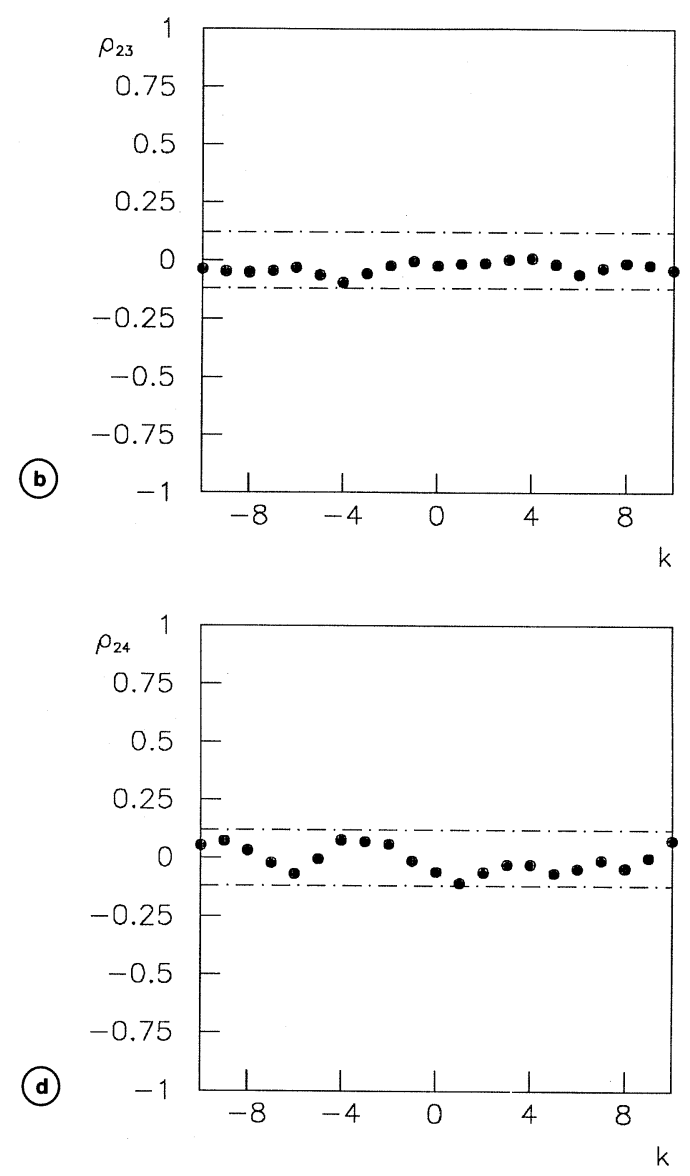

Fig. 9a-d. Cross-correlation coefficients with different lag: a) and b) report the results obtained from the residual voltage time series and the daily air temperature; c) and d) report the results obtained from the residual voltage time series and the humidity time series. 


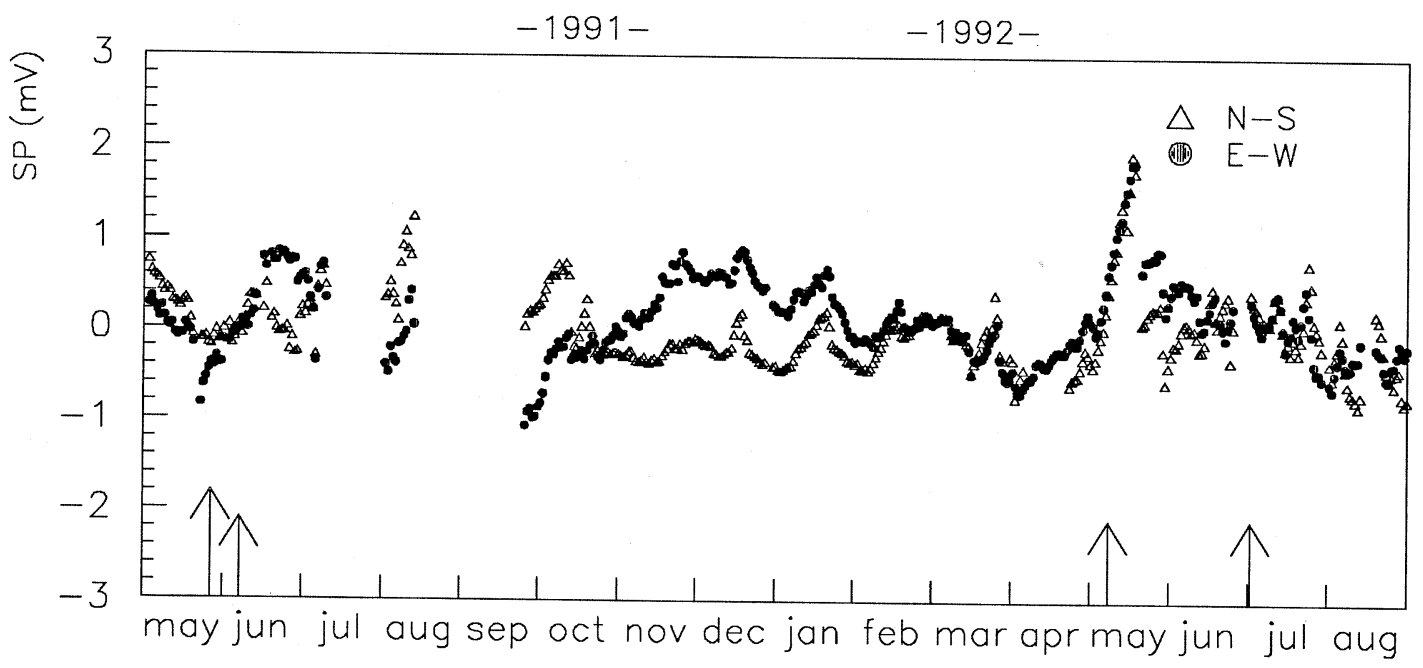

Fig. 10. The graph shows the main earthquakes (arrows) of the period and the residual self-potential time series.

On the other hand, in July 1992 an earthquake $(M=3.2)$ occurred and we did not note any change in the temporal dynamics of the self-potential time series. To explain this phenomenon we recall that in many geological conditions, with particular depth conductivity distributions, we do not observe a difference voltage at the measuring probes (Patella, 1988) when we have a charge motion in the hipocentral area. We note also that the earthquake epicentre, recorded in July 1992, is not localized near other epicentres and it is far $(40 \mathrm{~km})$ from the measuring point.

The discriminated anomalies have a very low probability to be correlated with random fluctuations around the mean value. The residual values have a normal distribution and the probability that many consecutive values are above the threshold of $2 \sigma$ is very low.

To conclude our analysis we note that the electrical seismic prediction is extremely complex, but the preliminary results are interesting even if the analyzed period is short. At present we can only investigate and localize the anomalies in the residual time series but, in the near future, we will be able to estimate their occurrence probability.

\section{Conclusions}

In this study we obtained the first preliminary results on the efficiency of electrotelluric precursors of earthquakes. The phenomenon is complex and the physical laws that govern the process are not completely known. In this work we suggested a methodological approach to the study of the self-potential time series for seismic prediction. In our opinion only a preliminary statistical and spectral analysis of the selfpotential residual time series can give useful information on the role of electrotelluric precursors in the problem of seismic prediction. The preliminary results, discussed in the previous section, show in many cases a temporal dynamic change in the time series when an earthquake occurs. In the near future we plan to implement the measuring points, the newly collected data will allow us to evaluate the statistical efficiency of these electric precursors.

\section{Acknowledgements}

We thank Profs. V. Cuomo and D. Patella who suggested and encouraged this research 
and we are grateful to Profs. M. Macchiato and C. Serio for their suggestions on the statistical analysis of the data.

Finally we thank Dr. Leggeri and Dr. M. Tramutoli for giving us useful information on the local earthquake sequences.

\section{REFERENCES}

ANDERSEN, N. (1974): On the calculation of filter coefficients for maximum entropy spectral analysis, Geophysics, 39, 545-557.

Box, G.E.P. and G.M. JENkINS (1976): Time Series Analysis Forecasting and Control (Holden Day, Oakland, California).

Burg, J.P. (1978): A new analysis technique for time series data, Modern Spectrum Analysis (IEEE Press, New York) pp. 42.

BurTon, P.W. (1985): Electrical earthquake prediction, $\mathrm{Na}$ ture, 315, 370-371.

JENKIns, G.M. and D.G. WATTS (1968): Spectral Analysis and its Applications (Holden-Day, San Francisco).
Mogi, K. (1985): Earthquake Prediction (Academic Press, Tokyo).

Nur, A. (1972): Dilatancy pore fluids, and premonitory variations of $t_{p} / t_{s}$ travel times, Bull. Seismol. Soc. Am., 62, 1217-1222.

Patella, D. (1988): Variazioni anomale dei parametri elettrici delle rocce quali precursori sismici, in Aree sismogenetiche e rischio sismico in Italia, edited by $\mathrm{E}$. BOSCHI and M. DRAGONI.

Pellettieri, A. (1992): Un tentativo di cronistoria sismica per la città di Potenza dall'antichità all'anno $1000, \mathrm{Bol}$ lettino Storico della Basilicata (Edizioni di Storia e Letteratura), n. 8.

RikitAKE, T. (1979): Classification of earthquake precursors, Tectonophysics, 54, 293-309.

RikitAKE, T. (1988): Earthquake prediction: an empirical approach, Tectonophysics, 148, 195-210.

SORNETTE, A. and D. SORNETTE (1990): Earthquake rupture as a critical point: consequences for telluric precursors, Tectonophysics, 179, 327-334.

VArotsos, P. and K. AleXopoulos (1984a): Physical properties of the variations of the electric field of the Earth preceding earthquakes, Tectonophysics, 110, 99-125.

VArotsos, P. and K. Alexopulos (1984b): Physical properties of the variations of the electric field of the Earth preceding earthquakes 2: Determination of epicentre and magnitude, Tectonophysics, 110, 99-125. 